\title{
Measurements of the surface tension of the Iron- Silicon system using electromagnetic levitation
}

\author{
Robert BROOKS', Andrew Cameron ${ }^{2}$ \\ ${ }^{1}$ Centre for Materials Measurement and Technology, National Physical Laboratory, Queens Road, \\ Teddington, UK, TW11 OLW \\ ${ }^{2} \mathrm{BOC}$ Research and Development, Rotherham, UK
}

\begin{abstract}
Surface tension measurements have been carried out on binary alloys of iron and silicon, and on pure iron using the levitated drop technique. The alloy compositions (atomic percent) chosen were $\mathrm{Fe}+25 \% \mathrm{Si}, \mathrm{Fe}+37.5 \% \mathrm{Si}$, $\mathrm{Fe}+50 \% \mathrm{Si}, \mathrm{Fe}+62.5 \% \mathrm{Si}, \mathrm{Fe}+75 \% \mathrm{Si}$. Attempts were also made to measure the surface tension of pure silicon by this method, which unfortunately resulted in only one successful measurement. Surface tension is derived from measurements of the oscillation frequencies of a liquid droplet levitated in the magnetic field of a radio frequency coil, which also inductively heats the sample. It is therefore necessary for the material under study to be electrically conducting, and whilst the alloy samples levitated readily, it was necessary to pre-heat the silicon to about $800^{\circ} \mathrm{C}$ before it would levitate. The difficulties the electrical conduction of silicon imposes on the measurement are discussed. In order to produce high purity samples, with low oxygen contents, samples were prepared in a cold crucible levitator under an argon $+10 \%$ hydrogen atmosphere.
\end{abstract}

The surface tension values obtained in this study were:

$\begin{array}{ll}\mathrm{Fe} & 1.89-0.44 \times 10^{-3}\left(\mathrm{~T}-1537\left[{ }^{\circ} \mathrm{C}\right]\right) \mathrm{Nm} \\ \mathrm{Fe}+25 \% \mathrm{Si} & 1.69-0.19 \times 10^{-3}\left(\mathrm{~T}-1263\left[\left[^{\circ} \mathrm{C}\right]\right) \mathrm{Nm}\right. \\ \mathrm{Fe}+37.5 \% \mathrm{Si} & 1.51-0.24 \times 10^{-3}\left(\mathrm{~T}-1247\left[{ }^{\circ} \mathrm{C}\right]\right) \mathrm{Nm} \\ \mathrm{Fe}+50 \% \mathrm{Si} & 1.17+0.19 \times 10^{-3}\left(\mathrm{~T}-1407\left[{ }^{\circ} \mathrm{C}\right]\right) \mathrm{Nm} \\ \mathrm{Fe}+62.5 \% \mathrm{Si} & 1.02-0.14 \times 10^{-3}\left(\mathrm{~T}-1298\left[\left[^{\circ} \mathrm{C}\right]\right) \mathrm{Nm}\right. \\ \mathrm{Fe}+75 \% \mathrm{Si} & 0.87+0.24 \times 10^{-3}\left(\mathrm{~T}-1242\left[{ }^{\circ} \mathrm{C}\right]\right) \mathrm{Nm}\end{array}$

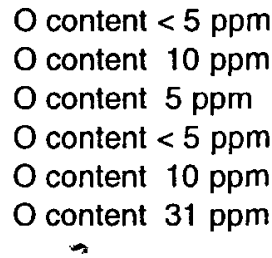

$\rightarrow$

A single value for the surface tension of silicon of $0.78 \mathrm{Nm}$ at $1900^{\circ} \mathrm{C}$ was obtained.

Key Words: alloys, iron, levitation, silicon, surface tension

\section{Introduction}

The surface tension of iron-silicon is of interest to a number of metallurgical process, and has been studied previously using traditional measurement methods, such as sessile drop, and maximum bubble pressure. In this study the levitated drop method is used, as previous work has shown it to be reliable, and less prone to contamination of the sample than other techniques.

\section{Sample Preparation}

Alloys were prepared from samples of Johnson Matthey Specpure ${ }^{B}$ Iron and Silicon metals in a Crystallox HB40 cold crucible with a $450 \mathrm{kHz}, 40$ $\mathrm{kW}$ RF coil. The relative quantities of each material were weighed, place in the crucible, and after degassing the apparatus with an atmosphere of $\mathrm{Ar}+$ $10 \% \mathrm{H}_{2}$, inductively heated. Initially the iron heated and melted, alloying with the silicon. The resultant melt was levitated in the crucible and the atmosphere replaced with one of hydrogen. In initial experiments an oxide layer could be seen on the high silicon samples. Hydrogen was found to reduce this layer, but was adsorbed into the metal, forming bubbles in the solidified metal. Cooling the sample in an argon atmosphere prevented the bubble formation. Table 1 shows the alloy compositions used in this study, from post production analysis.

Table 1 Composition of Fe Si alloys

\begin{tabular}{ccc} 
Sample & wt\% Si & mol\% Si \\
\hline 1 & 14.36 & 25.8 \\
2 & 23.18 & 37.95 \\
3 & 33.46 & 50.62 \\
4 & 45.6 & 62.53 \\
5 & 60.14 & 74.74 \\
\hline
\end{tabular}

The pure silicon samples could not be directly induction heated and a susceptor was needed to preheat the samples. Experiments with molybdenum and tantalum susceptors proved unsuccessful and so a graphite block was used. Care was taken to ensure the graphite did not come into contact with the melt, and it was preheated a number of times before use to reduce the risk of lose particles contaminating the melt Subsequent analysis of the buttons did not find any significant levels of carbon. 


\section{Experimental Procedure}

Surface tensions were measured using the levitated drop technique, in which a small droplet of metal is levitated and melted in the magnetic field of a radio frequency $(450 \mathrm{kHz})$ coil. In the apparatus at NPL the coil is wound around a silica tube which acts as the environmental chamber. An atmosphere of purified argon and hydrogen is flowed through the tube, the ratio of the gases being varied to provide coarse temperature control. Fine temperature control is obtained by varying the power of the generator, and hence the position of the droplet in the electromagnetic field, and thus the induction heating. A turntable at the bottom of the tube allows multiple samples to be loaded sequentially.

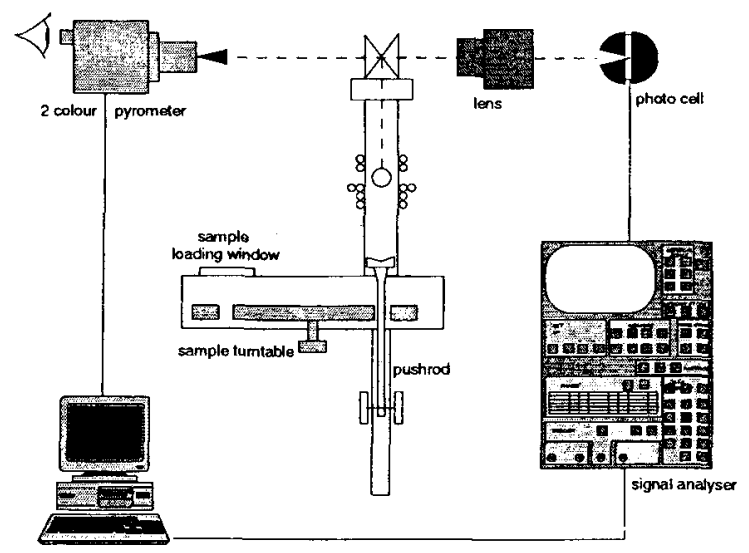

Figure 1: Experimental setup

Once levitated and molten inhomogeneities in the magnetic field cause the droplet to precess within the tube, which distorts the shape of the droplet. The equilibrium shape is then restored in a series of oscillations, the frequency of which are determined by the surface tension of the liquid. The continued precession of the droplet means that it will continue to oscillate whilst levitated. Surface tension can be determined from the equation due to Lord Rayleigh:

$$
\gamma=3 \pi \cdot m \cdot \omega^{2} / 8
$$

were $\gamma=$ surface tension of the liquid, $m=$ mass of the droplet, and $\omega=$ the Rayleigh oscillation frequency. To obtain the frequency the image of the droplet is projected through a slit onto a photodiode. This sees the changing diameter of the drop and produces a varying electrical signal. Fourier analysis of the signal resolves the oscillation frequencies. Temperature is measured with an optical pyrometer. Rayleigh (1) considered oscillations around a sphere, which provide a single frequency. However, in practice, this technique normally provides a spectrum of three or five oscillation frequencies, plus translation frequencies. Cummings and Blackburn (2) showed that the splitting of the frequencies is due to the nonspherical shape of the droplet, and that the values are raised by the pressure of the magnetic field. To obtain the Rayleigh frequency $\left(\omega_{\mathrm{R}}\right)$ a correction is needed:

$$
\omega_{R}^{2}=\frac{1}{5} \sum_{m=1-5} \omega_{m}^{2}-\omega_{T}^{2}\left\{1.90+1.20\left(\frac{g}{2 a\left(2 \pi \omega_{T}\right)^{2}}\right)^{2}\right\},
$$

It has been demonstrated that measurements made terrestrially using this correction agree well with those made in microgravity, where the droplet is spherical, and a single frequency is obtained (3).

A great deal of experience has been gained with the experimental apparatus described, with a variety of metals and alloys. However, for silicon some modifications were required to pre-heat the sample to approximately $850^{\circ} \mathrm{C}$ before it would conduct sufficiently to levitate. Initially a Tantalum susceptor was placed in the tube, to be removed at the appropriate time. Whilst it successfully heated the silicon, it also heated the coil to an unacceptable level, causing the cooling water to boil, and the coil to burn out. Enlarging the coil diameter prevented the problem and provided rapid heating, but the magnetic field produced distorted the drop shape so that clear oscillation frequencies could not be resolved.

A second method of heating using a simple resistance heater wound around the tube, away from the coil. The silicon could be heated sufficiently and lowered into the coil where it would levitate. A second problem then arose: as the silicon heated its conductivity increased, causing it to levitate higher in the coil. This reduces the efficiency of the induction heating, and the sample cools, reducing the conductivity, and lowering it back into the coil. The sample could therefore levitate up and down the tube for many minutes, reaching temperatures of $1400^{\circ} \mathrm{C}$ without melting. On one occasion the gases and power were adjusted to provide rapid heating and the sample reached an indicated temperature in excess of $1900^{\circ} \mathrm{C}$ before oscillation measurements could be made. A surface tension value of 0.780 $\mathrm{Nm}$ was determined from this one measurement, which would suggest that the surface tension at the melting point is higher than the $0.75 \mathrm{Nm}$ often reported (4).

\section{Results}

Results of surface tension measurements on the range of alloys are given in table 2 , in the form:

$$
\gamma_{\mathrm{Fe}+\mathrm{x} \% \mathrm{si}}=\gamma_{\mathrm{mp}}+\mathrm{d} \gamma / \mathrm{dT} \times 10^{-3}\left(\mathrm{~T}-\mathrm{T}_{\mathrm{mp}}\right)
$$

Table 2 Surface tension results

$\begin{array}{cccc}\% \text { Si } & \begin{array}{c}\text { melting } \\ \text { point } \\ { }^{\circ} \mathrm{C}\end{array} & \gamma_{\mathrm{mp}} & \mathrm{d} \gamma / \mathrm{dT} \\ 0 & 1537 & \mathrm{Nm} & \mathrm{Nm} \times 10^{3} \\ 25 & 1263 & 1688 & -0.44 \\ & & & -0.19\end{array}$




$\begin{array}{cccc}\% \text { Si } & \begin{array}{c}\text { melting } \\ \text { point } \\ { }^{\circ} \mathrm{C}\end{array} & \begin{array}{c}\gamma_{\mathrm{mp}} \\ \mathrm{Nm}\end{array} & \mathrm{Nm} / \mathrm{dT} \\ 37.5 & 1247 & 1507 & -0.25 \\ 50 & 1407 & 1173 & 0.19 \\ 62.5 & 1398 & 1019 & -0.14 \\ 75 & 1242 & 874 & 0.24\end{array}$

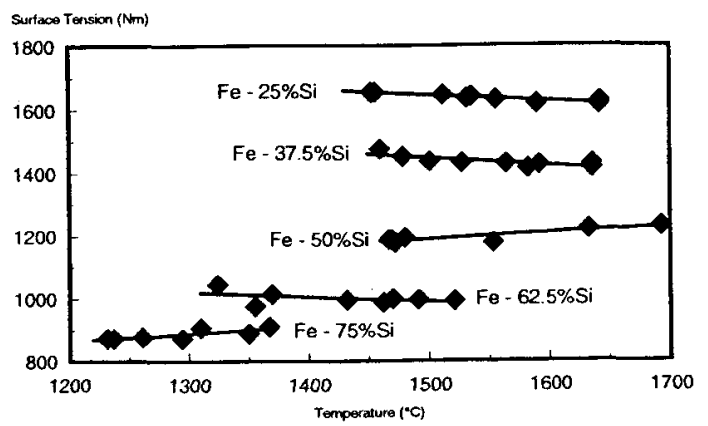

Figure 2: Surface tension values for various $\mathrm{Fe}-\mathrm{Si}$ alloys

Following the surface tension measurements 3 randomly selected samples of each composition were sent for oxygen analysis by British Steel. The results are shown in table 3 .

\begin{tabular}{ccc}
$\% \mathrm{Si}$ & $\begin{array}{c}\text { total oxygen } \\
\mathrm{ppm}\end{array}$ & $\begin{array}{c}\text { variation } \\
\mathrm{ppm}\end{array}$ \\
\hline 0 & $<5^{*}$ & 0 \\
25 & 10 & 2 \\
37.5 & 5 & 1 \\
50 & $<5^{*}$ & 0 \\
62.5 & 10 & 4 \\
75 & 31 & 3
\end{tabular}

*limit of analysis

\section{Discussion}

B J Keene reviewed surface tension values for iron binary alloys, which covers the majority of work on the $\mathrm{Fe}-\mathrm{Si}$ system (5). The results from this work are higher than those he reported when compared at $1550^{\circ} \mathrm{C}$. However, it should be noted that this temperature is beyond the range at which the higher silicon content alloys were measured in this study, and therefore the values are extrapolated. The slope for the $75 \% \mathrm{Si}$ alloy is positive. This can be attributed to its high oxygen content, but this causes the extrapolated surface tension value to be far higher than that expected of the uncontaminated alloy.

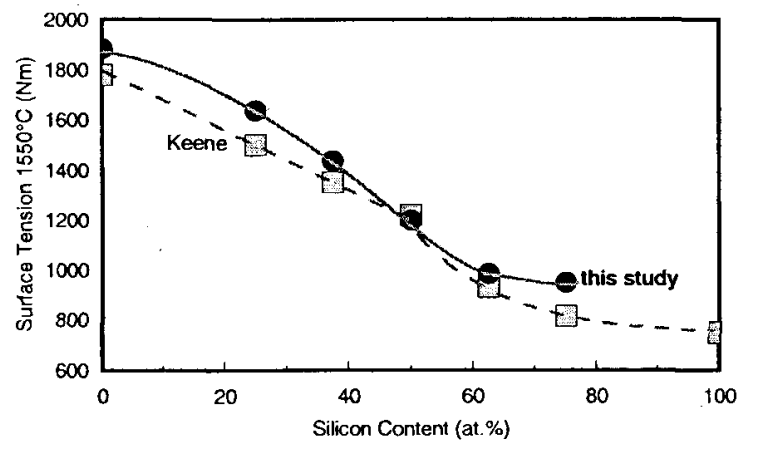

Figure 3: Comparison of mean data from Keene's review (5)

The positive coefficient found with the $50 \% \mathrm{Si}$ alloy is more puzzling, as the total oxygen concentration was below the detectable level (5ppm). This result may be attributable to increasing iron concentrations at the surface of the melt with increasing temperature. The higher oxygen contents found in the $37.5 \%$, and $62.5 \%$ may be associated with the surface structure becoming $\mathrm{Si}$ rich around these compositions (5), and thus reacting more strongly with the surrounding atmosphere.

\section{Coñclusions}

Due to the high solubility of oxygen in silicon it is difficult to obtain values for the uncontaminated metal, or alloys. Further work is required to study the activity of oxygen in $\mathrm{Fe}-\mathrm{Si}$ alloys. However the levitated drop technique has been demonstrated to provide acceptable surface tension values. This work has shown that the NPL levitation apparatus is unsuitable for measurements on semiconductors in its present arrangement. Successful measurements on silicon by Egry and co-workers would show that a conical coil design, which contains more of the droplet profile, and thus a more even heat distribution in the $\mathrm{z}$-axis, is preferable.

\section{REFERENCES}

1) Lord Rayleigh: Proc. Roy. Soc. (London), Ser. A 29 1879

2) D Cummings and D Blackburn: J. Fluid Mech. $221(1991)$

3) I Egry, $1998 \mathrm{~J}$. Jpn. Soc. Microgravity Appl. 15, 215Space

4) B Keene: Int. Mat. Reviews 384 (1993)

5) B Keene: Int. Mat. Reviews 331 (1988)

\section{Acknowledgement}

The authors would like to thank Lynda Troy for her help in modifying the apparatus to levitate silicon. 